\title{
How Learning Goal Orientation Fosters Leadership Recognition in Self-managed Teams \\ A Two-stage Mediation Model
}

Lee, Yih-Teen; Paunova, Minna

Document Version

Accepted author manuscript

Published in:

Applied Psychology

DOI:

10.1111/apps. 12101

Publication date:

2017

License

Unspecified

Citation for published version (APA):

Lee, Y-T., \& Paunova, M. (2017). How Learning Goal Orientation Fosters Leadership Recognition in Selfmanaged Teams: A Two-stage Mediation Model. Applied Psychology, 66(4), 553-576.

https://doi.org/10.1111/apps.12101

Link to publication in CBS Research Portal

\section{General rights}

Copyright and moral rights for the publications made accessible in the public portal are retained by the authors and/or other copyright owners and it is a condition of accessing publications that users recognise and abide by the legal requirements associated with these rights.

\section{Take down policy}

If you believe that this document breaches copyright please contact us (research.lib@cbs.dk) providing details, and we will remove access to the work immediately and investigate your claim.

Download date: 26. Apr. 2023
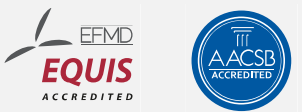


\section{How Learning Goal Orientation Fosters Leadership Recognition in Self-Managed Teams: A Two-Stage Mediation Model Yih-Teen Lee and Minna Paunova \\ Journal article (Accepted version)}

This is the peer reviewed version of the following article: How Learning Goal Orientation Fosters Leadership Recognition in Self-Managed Teams : A Two-Stage

Mediation Model. / Lee, Yih-Teen; Paunova, Minna. In: Applied Psychology, 27.06.2017, which has been published in final form at http://dx.doi.org/10.1111/apps.12101

This article may be used for non-commercial purposes in accordance with Wiley Terms and Conditions for Self-Archiving

Uploaded to Research@CBS: July २०17 


\title{
LEARNING GOAL ORIENTATION AND LEADERSHIP RECOGNITION
}

How Learning Goal Orientation Fosters Leadership Recognition in Self-Managed Teams: A

Two-Stage Mediation Model

\author{
Yih-teen Lee, Ph.D. \\ (ylee@,iese.edu) \\ IESE Business School \\ University of Navarra \\ Avda. Pearson 21 \\ Barcelona 08034, Spain \\ Tel.: +34 932534200 \\ Fax: +34932534343 \\ Minna Paunova, Ph.D. \\ (mp.ibc@cbs.dk) \\ Copenhagen Business School \\ Dalgas Have 15, $2 \varnothing .051$ \\ 2000 Frederiksberg, Denmark \\ Tel.: +4538155662 \\ Mob.: +45 52220832
}

* Two authors contributed equally to the paper.

Lee, Y.-t., \& Paunova, M. (in press). How learning goal orientation fosters leadership recognition in selfmanaged teams: A two-stage mediation model. Applied Psychology: An International Review. 


\begin{abstract}
Defined as a mental framework for how individuals interpret and respond to achievement situations, learning goal orientation (LGO) has received increasing attention in organizational research. However, its effect on leadership, especially in contexts absent of formal leadership, remains understudied. Drawing on social exchange theory, we propose and test an individuallevel two-stage process model of generalized exchange linking LGO and leadership recognition in self-managed teams. Specifically, we posit that learning-oriented individuals will tend to feel safer in self-managed teams, which will enable and sustain their engagement in contextual role behavior. Such behavior, in turn, will be reciprocated with recognition of these individuals as leaders. We use a multiphase, multi-informant approach $(n=287)$, and we find that felt safety mediates the effect of LGO on contextual role behavior, but that contextual role behavior alone does not mediate the effect of LGO on leadership recognition. LGO has an indirect effect on leadership recognition through the joint mediation of felt safety and contextual role behavior. Our results offer insight on the link between LGO and leadership, with practical implications for people working in self-managed teams.
\end{abstract}

Keywords: learning goal orientation, leadership, self-managed teams, felt safety, contextual role behavior 


\section{LEARNING GOAL ORIENTATION AND LEADERSHIP RECOGNITION}

How Learning Goal Orientation Fosters Leadership Recognition in Self-Managed Teams: A Two-Stage Mediation Model

Goal orientation, a mental framework for how individuals interpret and respond to achievement situations (Brett \& VandeWalle, 1999; Dweck \& Leggett, 1988), has received increasing attention in recent organizational research (e.g., Button, Mathieu, \& Zajac, 1996; DeRue \& Wellman, 2009; Payne, Youngcourt, \& Beaubien, 2007). Of particular interest has been the idea that individuals with a learning goal orientation (LGO) set goals in terms of competence development instead of ability demonstration per se (Dweck, 1986; Dweck \& Leggett, 1988), and thus enact more functional self-regulation that leads to better performance in the long term (Porath \& Bateman, 2006; VandeWalle, Brown, Cron, \& Slocum, 1999; see also meta-analyses of Cellar et al., 2011; Payne et al., 2007). Scholars have just started to investigate the effects of LGO on social behaviors such as teaming up, which have positive interpersonal consequences (Poortvliet \& Darnon, 2010; Porter, 2005). In this paper, we extend research on LGO in social domains, specifically, on how LGO fosters leadership recognition in self-managed teams, by proposing a process model integrating the intrapersonal and interpersonal outcomes of LGO. We focus on the context of self-managed teams for several reasons.

Modern organizations have increasingly moved from hierarchical to flatter structures, allocating larger decision-making latitude to employees across organizational levels. Notable examples include the Holacracy at Zappos, the radical democratization at Semco, and the company-wide adaptation of self-managed units at Haier. Accordingly, self-managed teams gain increasing popularity in organizations (Erez, LePine, \& Elms, 2002). In contexts absent of formal leadership structures, each member may carry out leadership functions informally, and be recognized or accepted as leader in return (Bass, 1990). Leadership recognition, which suggests 


\section{LEARNING GOAL ORIENTATION AND LEADERSHIP RECOGNITION}

leadership resides largely in the recognition of leadership by followers, is therefore important in these contexts (Brown, 2012; Meindl, 1995). Specifically, it indicates teammates' state of readiness to grant leadership to a focal person (DeRue \& Ashford, 2010), which enables the focal person to effectively exercise leadership and be part of the influence dynamics in the team.

Recent research has started to pay attention to the link between LGO and leadership. For example, LGO has been found to boost leadership effectiveness (Hendricks \& Payne, 2007). Similarly, individuals with high LGO are more likely to be seen as transformational leaders (Coad \& Berry, 1998; Sosik, Godshalk, \& Yammarino, 2004), and LGO is found to facilitate leadership development (DeRue \& Wellman, 2009; Dragoni, Tesluk, Russell, \& Oh, 2009). However, important omissions exist in our understanding of the LGO_-leadership link. First, the few studies examining the relationship between LGO and leadership focus primarily on established formal leaders. Thus, little is known about the role of LGO for leadership in settings characterized by no formal hierarchical structures. Second, studies tend to associate LGO and leadership directly (e.g., Coad \& Berry, 1998; Sosik et al., 2004) without addressing the intermediate mechanisms. Yet, we contend that it is crucial to investigating the intermediate processes between LGO and leadership, consistent with earlier studies suggesting that the effects of LGO on distal social outcomes arise through intermediate processes (e.g., Chen, Gully, Whiteman, \& Kilcullen, 2000; Porath \& Bateman, 2006; VandeWalle \& Cummings, 1997). As a result, we aim to answer the following research questions: (1) does individuals' LGO affect their likelihood to be recognized as leaders in self-managed teams? If so, (2) what are the mediators that channel the effect of LGO on leadership recognition?

We draw on social exchange theory (Blau, 1964; Cropanzano \& Mitchell, 2005) to examine the effect of LGO on leadership recognition. According to social exchange theory, 


\section{LEARNING GOAL ORIENTATION AND LEADERSHIP RECOGNITION}

actors interact in social systems and exchange various types of economic and social resources, including intangible and symbolic ones (e.g., love, trust, and status), following specific rules and norms of exchange (Cropanzano \& Mitchell, 2005). We conceive of the interaction among members of self-managed teams that links LGO and leadership recognition as a social exchange relationship, because in self-managed teams members may assume leadership roles and responsibilities and be reciprocated accordingly. LGO can help us understand better the intrapersonal process that sets off the interpersonal process of social exchange. In fact, the relationship between LGO and leadership recognition reflects generalized exchange (Yamagishi \& Cook, 1993), which refers to the indirect giving and receiving of benefits among three or more people often in non-specified and non-symmetrical ways (Willer, Flynn, \& Zak, 2012). Specifically, leadership recognition can be considered as a symbolic social resource team members offer to a focal individual in exchange for the value this individual brings to the collective.

Two intermediate factors are critical in facilitating this social exchange process. First, individuals' felt safety (i.e., a person's perception of the degree of interpersonal threat; Nembhard \& Edmondson, 2010), is particularly relevant to the social exchange process because it determines individuals' willing contribution of ideas and actions (Edmondson \& Lei, 2014). This is especially true in self-managed teams where there is a general lack of clarity around roles, procedures, and authority relations (Bunderson \& Boumgarden, 2010). This makes the outcomes of interaction among team members difficult to expect and predict, and leads to a heightened level of interpersonal risk. Second, individuals' contextual role behaviors (i.e., discretionary non-job-specific behaviors contributing to the social environment of work; Borman \& Motowidlo, 1993) serve as an important resource for teams that is rewarded or reciprocated 


\section{LEARNING GOAL ORIENTATION AND LEADERSHIP RECOGNITION}

with leadership recognition. We propose a two-stage process model that links LGO and leadership recognition in self-managed teams, and formally examine the mediation mechanisms in our hypotheses testing. Our choice to focus on these two mediators is also consistent with the definition of goal orientation as a mental framework of how individuals interpret and respond to achievement situations (Brett \& VandeWalle, 1999; Dweck \& Leggett, 1988). LGO is expected to enable functional self-regulation so that learning-oriented individuals (1) will interpret ambiguous situations in self-managed teams as less socially threatening (hence they will feel safer), and (2) will respond to such situations with discretionary contextual role behaviors. From a social exchange perspective, this will be reciprocated with the recognition of leadership.

Our study contributes to the literature in several important ways. First, we extend goal orientation research by examining the association between LGO and leadership recognition in self-managed teams, which is theoretically important in light of nascent research attention to the effect of LGO in socio-behavioral domains. Whereas previous studies focus primarily on the effect of LGO on focal individuals (e.g., their learning, leadership development, etc.), our paper contributes to the understanding of the effect of LGO on how the focal individuals are perceived by others. Second, drawing on social exchange theory, we propose a model with two mechanisms mediating LGO's effects. This model integrates both intrapersonal (i.e., LGO - felt safety - contextual role behavior) and interpersonal (i.e., LGO - contextual role behavior leadership recognition) aspects of exchange into a single model, thus offering important implications to social exchange theory itself (Emerson, 1976; Shore, Coyle-Shapiro, Chen, \& Tetrick, 2009). Our study sheds light on the specific mechanisms and processes through which the symbolic resource of leadership is granted in exchange for one's interpretation and response to social situations associated with LGO. 


\section{LEARNING GOAL ORIENTATION AND LEADERSHIP RECOGNITION}

\section{Theoretical Development and Hypotheses}

As a mental framework that activates specific processes of self-regulation, which modulate individual thought, affect, and behavior in goal-attainment situations (Brett \& Vandewalle, 1999; Porath \& Bateman, 2006), LGO channels individual attention towards developing ability and competence for accomplishing future tasks, and not necessarily towards performing well (and looking good) at current ones (Porath \& Bateman, 2006; VandeWalle et al., 1999). In other words, LGO tends to trigger effective self-regulation so that individuals interpret and respond to achievement situations in functional ways. In that, LGO differs from performance goal orientation (PGO), which drives individuals to demonstrate competence and gain favorable judgment (Dweck, 1986; Dweck \& Leggett, 1988).

Scholars have started paying attention to the social effects of LGO beyond learning and work performance, including leadership (Coad \& Berry, 1998; Sosik et al., 2004). Extant studies suggest that LGO has a positive effect on leadership-related outcomes, and that LGO fosters functional behaviors in social interaction. However, there has been a lack of elaboration of the intrapersonal dynamics that may stimulate the interpersonal outcomes of LGO. As a mental framework, LGO is undoubtedly a distal predictor of interpersonal outcomes. Learning orientation translates into concrete mental states and specific behaviors, and this is how its interpersonal outcomes such as leadership recognition materialize. Learning-oriented individuals are more willing to share critical information at work, and engage in backing up behaviors (Poortvliet, Janssen, Van Yperen, \& Van de Vliert, 2007; Porter, 2005). From a social exchange perspective, the behavioral tendencies of learning-oriented individuals may explain why these individuals are recognized as more leader-like. Learning-oriented individuals' cooperativeness (concern for others, Poortvliet et al., 2007, or other orientation, Parsons, 1951; see also Burns, 


\section{LEARNING GOAL ORIENTATION AND LEADERSHIP RECOGNITION}

1973) shape the nature of social exchange in teams by stimulating the conditions for generalized reciprocity. By being willing to offer socially valuable resources to the team in the first place, learning-oriented individuals receive recognition in return.

We propose a two-stage process model of social exchange that links LGO and leadership recognition in self-managed teams. Specifically, we expect that felt safety will explain why individuals are willing to offer functional behaviors to the team (i.e., felt safety will mediate the link between LGO and contextual role behavior), whereas contextual role behavior will explain why leadership recognition is reciprocated (i.e., contextual role behavior will mediate the link between LGO and leadership recognition). We present our conceptual model in Figure 1.

Insert Figure 1 about here

\section{Felt Safety Mediates the Effect of LGO on Contextual Role Behavior}

Safety refers to the freedom that individuals feel in expressing themselves without negative repercussions in terms of their image or career (Kahn, 1990), or the feeling that "one is not at risk of embarrassment or rejection in a particular setting or role" (Edmondson \& Roloff, 2009: 186). As a perception of interpersonal threat (Nembhard \& Edmondson, 2010), felt safety is embedded in social interaction and plays a critical role in social exchange that involves discretionary behavior. From a social exchange perspective, individuals usually assess the costs and benefits involved in engaging in certain behaviors before they take action. Felt safety will provide people with psychological comfort to engage in discretionary behaviors, particularly when the rules, resources and norms of exchange are less clear, as in self-managed teams. Emotions such as safety shape social exchange processes because emotions influence actors' 


\section{LEARNING GOAL ORIENTATION AND LEADERSHIP RECOGNITION}

perception and interpretation of exchange partners and the exchange situation itself(Lawler \& Thye, 1999). Feeling safe in self-managed teams thus helps individuals take the risk involved in generalized exchange when the reciprocity targets and norms are not specified (Willer et al., 2012).

In the current study, we treat felt safety as an individual-level outcome of LGO (that is, as consequence of how individuals interpret the situation of social exchange), and contend that LGO will make individuals feel safer for the following reasons. First, learning-oriented individuals tend to see challenging situations as an opportunity to learn and improve themselves (Ashford, Blatt, \& VandeWalle, 2003; VandeWalle \& Cummings, 1997). Because of their tendency toward seeking self-improvement instead of self-validation information (Janssen \& Prins, 2007), individuals with higher LGO experience lower ego costs upon receiving negative feedback or confronting adversity in social interaction (VandeWalle \& Cummings, 1997). Furthermore, as their needs for self-development and growth supersede their safety needs (e.g., fear of failure; Dykman, 1998), learning-oriented individuals are less likely to feel anxious (i.e., will enjoy higher levels of felt safety), particularly in situations where there is something at stake (see meta-analytical review of Payne et al., 2007).

Second, learning-oriented individuals tend to (1) use self-referenced criteria in evaluating one's performance (instead of comparing themselves with others, i.e., otherreferenced standard; Poortvliet, Anseel, Janssen, Van Yperen, \& Van de Vliert, 2012), (2) face less social comparison pressures and do not perceive others as enemies or competitors (Poortvliet \& Darnon, 2010). As a result, they generally feel less threatened in challenging and ambiguous situations such as those present in self-managed teams, and are more willing to demonstrate contextual role behavior, which may or may not be reciprocated directly. Moreover, learning- 


\section{LEARNING GOAL ORIENTATION AND LEADERSHIP RECOGNITION}

oriented individuals generally have higher concern for others because they do not aim to outperform others and feel safer in social interaction (Poortvliet et al., 2007). All this suggests that felt safety mediates the link between LGO and contextual role behavior. Thus, we posit that: Hypothesis 1: Felt safety mediates the effect of LGO on contextual role behavior in selfmanaged teams.

\section{Contextual Role Behavior Mediates the Effect of LGO on Leadership Recognition}

Although there is only limited research on the relationship between LGO and leadership recognition, a careful scrutiny of the nomological network of LGO, and of leadership emergence (e.g., Foti \& Hauenstein, 2007; Taggar, Hackett, \& Saha, 1999), indicates that such relationship is highly likely, particularly if mediated by behaviors such as context role behavior. Contextual role behavior refers to non-job-specific behaviors beneficial to one's social environment at work such as cooperating with and helping coworkers, volunteering, and persisting with extra effort when facing difficulties (Borman \& Motowidlo, 1993; DeRue \& Morgeson, 2007; LePine, Hanson, Borman, \& Motowidlo, 2000). We posit that contextual role behavior serves as a valuable resource in generalized social exchange for leadership recognition in self-managed teams, where learning-oriented individuals engage in indirect and asymmetrical exchange with the team. Research has indicated that LGO may foster positive interpersonal outcomes, so that, for example, learning-oriented employees develop and maintain favorable social exchange relationships with their supervisors (Janssen \& Van Yperen, 2004). We expect that learningoriented individuals are more likely to engage in contextual role behavior. Focusing on skill development and self-improvement, learning-oriented individuals tend not to feel under pressure to outperform others. As a result, they tend to be more cooperative and are more willing to share high-quality information with others (Janssen \& Van Yperen, 2004). Learning-oriented 


\section{LEARNING GOAL ORIENTATION AND LEADERSHIP RECOGNITION}

individuals would "choose to team up with coworkers and act in a much more benevolent way" (Poortvliet \& Darnon, 2010: 324). LGO is also related to taking initiative in improving current circumstances with both in-role and extra-role behaviors (i.e., proactivity; Crant, 2000), as well as to engaging with others and providing help (Chiaburu, Marinova, \& Lim, 2007). Overall, the expected social effects of LGO enable individuals to respond to challenging interpersonal and team situations with functional contextual role behavior.

Drawing on social exchange theory, and in line with functional leadership theory, we expect that individuals who engage in contextual role behavior are more likely to be perceived and recognized as leaders in self-managed teams. Earlier studies have offered insight on how exercising functional behaviors, such as satisfying the needs of others and fulfilling the roles necessary for a group to function successfully, can help individuals appear more leader-like and is reciprocated with higher status at work (Mann, 1959; Lord, 1977). Research largely corroborates this view and posits that those who fulfill key functions in terms of group needs are more likely to be viewed as leaders by their team members (Fleishman, Mumford, Zaccaro, Levin, Korotkin, \& Hein, 1991; Morgeson, DeRue, \& Karam, 2010). Contextual role behavior includes deeds that serve several functional and social needs of teams in both the team transition and action phases (e.g., providing feedback, challenging the team, solving problems, and supporting the social climate; see Morgeson et al., 2010). Hence, these behaviors will prompt teammates to accept the focal individual as more leader-like in return. Thus, we posit that:

Hypothesis 2: Contextual role behavior mediates the effect of LGO on leadership recognition in self-managed teams.

\section{Two-Stage Mediation of the Effect of LGO on Leadership Recognition}




\section{LEARNING GOAL ORIENTATION AND LEADERSHIP RECOGNITION}

Building on the relationships proposed in Hypotheses 1 and 2, we argue that felt safety and contextual role behavior jointly channel the effect of LGO toward leadership recognition. This is illustrated in the two-stage process model (Figure 1). In other words, in addition to the indirect effect via contextual role behavior as described in Hypothesis 2, there may be a second channel through which LGO influences leadership recognition. LGO will first influence individuals' self-regulation so that learning-oriented individuals will feel safer in self-managed settings. This feeling of safety derived from a learning focus (e.g., by using self-referenced competence standard, not seeing others as competitors, etc.) will then enable contextual role behavior and sustain the positive contributions to the generalized social exchange in teams. Engaging in contextual role behavior will in turn trigger and reinforce positive social exchange, so that peers will reciprocate by recognizing the focal learning-oriented individuals as more leader-like. As affective and behavioral regulatory mechanisms, felt safety and contextual role behavior are both implicated in the process of generalized social exchange, and mediate the relationship between LGO and leadership recognition in a joint way. More specifically, whereas felt safety functions as a distal mediator, contextual role behavior is a proximal mediator in this process.

Hypothesis 3: LGO has a positive indirect effect on leadership recognition in selfmanaged teams, mediated jointly through felt safety (as a distal mediator) and contextual role behavior (as a proximal mediator).

\section{Method}

\section{Sample}

We collected data from adults with work experience enrolled in an MBA program at a European business school. The program assigned individuals to teams of 7 to 9 members 


\section{LEARNING GOAL ORIENTATION AND LEADERSHIP RECOGNITION}

(average team size $=7.86, S D=0.72$ ). All teams were diverse in terms of gender, nationality and professional background. The average age was almost 28 years $(S D=2.01)$, and approximately 30 percent of participants were female. Participants were from 52 different nationalities, and on average had lived in more than two countries prior to participating in the study $(S D=1.24)$. In terms of background, participants reported approximately 100 different fields, and there were very few occasions in which two or more participants reported the same educational or professional background within any given team (i.e., maximizing skill complementarity by design).

There were no formally assigned leaders of these teams, hence they functioned as selfmanaged. We conducted web-based surveys at two time points, approximately two and a half months apart, that is, in the beginning (Time 1) and at the end (Time 2) of a term in which participants were required to work together and deliver multiple team-based assignments, ranging across disciplines such as organizational behavior, marketing, accounting, and finance. Teams remained fixed during the term and members interacted intensively in self-managed fashion to accomplish their tasks. The final sample consisted of 287 participants working in 36 teams.

\section{Measures}

As shown in Figure 1, we adopted a multiphase, multi-informant approach to data collection. We collected data at two times via self-report (i.e., LGO and felt safety) and peerassessment (i.e., contextual role behavior and leadership recognition). To avoid common method variance deriving from peer-assessed measures, for each target individual we randomly partitioned the inputs from peers so that we obtained measures of predictor and criterion variables from different sources (Podsakoff, MacKenzie, \& Podsakoff, 2012). Specifically, we 


\section{LEARNING GOAL ORIENTATION AND LEADERSHIP RECOGNITION}

obtained (1) a measure of contextual role behavior from one half of the team members, and (2) measures of leadership recognition from the other half of the team members. Analyses when the sources of ratings were reversed and those without applying random partitioning produced consistent results. Unless otherwise noted, all variables were measured on a seven-point Likerttype scale ranging from "strongly disagree" to "strongly agree".

Learning goal orientation. We measured LGO at Time 1 (right before the teams were formed) with a six-item scale adapted from Button et al. (1996). Example items are "The opportunity to do challenging work is important to me," and "I prefer to work on tasks that force me to learn new things" $(\alpha=.82)$.

Felt safety. We measured felt safety with the seven-item scale developed by Edmondson (1999) that includes items such as "Working with members of this team, my unique skills and talents are valued and utilized" and "No one on this team would deliberately act in a way that undermines my efforts." Felt safety was measured at Time 2. Participants were asked to refer to their team collaboration experiences in assessing how safe they felt. The Cronbach's alpha was relatively low compared to that of other scales $(\alpha=.67)$, yet was consistent with past research (e.g., Carmeli \& Gittell, 2009). Although the scale was initially designed to measure team-level psychological safety, we consider it appropriate to use it to measure individual-level feeling in this study. First, the wording of the measurement items is not referent-shifted. Instead, the consensus among lower-level units is what provides meaning to the higher-level construct (Chan, 1998). Moreover, the interclass correlation coefficient in our data $(\mathrm{ICC}=.07)$ is sufficiently low to support individual-level analysis. Hence, the scale captures the felt safety of each individual in a team. To further account for potential team-level confounding effects, we included team fixed effects in all equations (Antonakis et al., 2010). 


\section{LEARNING GOAL ORIENTATION AND LEADERSHIP RECOGNITION}

Contextual role behavior. We adapted a six-item scale of contextual performance from Van Scotter and Motowidlo (1996, as cited in DeRue and Morgeson, 2007) to measure contextual role behavior at Time 2. Participants were assessed by their team members with items such as "This team member encourages others to overcome their differences and get along", and "This team member takes the initiative to solve task-related problems" $(\alpha=.88)$.

Leadership recognition. We measured leadership recognition at Time 2 with the General Leadership Impression questionnaire put forward by Cronshaw and Lord (1987). The questionnaire includes 5 items such as, "How much leadership do you think was exhibited by this individual?" and "To what extent does this individual fit your image of a leader?" $(\alpha=.94)$. Participants assessed each of their team members on a seven-point scale that ranged from "not at all" to "very much".

Control variables. We controlled for performance goal orientation (PGO; Button et al., 1996; 5 items, $\alpha=.70$ ), because it may relate positively to contextual role behavior, given that it refers to the drive to demonstrate competence and look good in front of others (Chiaburu et al., 2007; Porath \& Bateman, 2006). We also controlled for age (in years) and gender (0 for male, 1 for female). We controlled for the number of countries an individual has lived in, due to the potential effect of international experience on leadership recognition (e.g., Daily, Certo, \& Dalton, 2000). Finally, as mentioned earlier, we controlled for team membership (i.e., the fact that individual-level data are nested in teams) with team dummy variables in order to account for team-level fixed effects (Antonakis, Bendahan, Jacquart, \& Lalive, 2010). Note that we do not apply multilevel modeling because our research questions focus on within-team variations, and by introducing team fixed effects we are already modeling the nested data structure (Antonakis et al., 2010; Preacher, Zyphur, \& Zhang, 2010). 


\section{LEARNING GOAL ORIENTATION AND LEADERSHIP RECOGNITION}

\section{Analytical Strategy}

First, we confirmed that there is a sufficient degree of agreement among team members in assessing specific target peers (James, Demaree, \& Wolf, 1984): for contextual role behavior, the average $r_{\mathrm{wg}}$ was $.89(M d n=.93)$, and for leadership recognition, the average $r_{\mathrm{wg}}$ was .88 $(M d n=.91)$. Second, we conducted a confirmatory factor analysis (CFA) using covariance matrix and maximum likelihood estimation to assess the discriminant validity of our constructs. Results of the expected five-factor structure (LGO, PGO, felt safety, contextual role behavior, and leadership recognition $)$ demonstrated acceptable fit with the data $\left(\chi^{2}(d f=359, \mathrm{n}=287)=\right.$ $566.68, p<.01 ; \mathrm{RMSEA}=.05 ; \mathrm{CFI}=.96 ; \mathrm{SRMR}=.06$ ), and all factor loadings were significant at the .05 level. However, the chi-square test of fit suggested that the number of indicators, and thus the number of parameters to be estimated is too large. The larger the order of the correlation or covariance matrix, the less likely the model is to fit well even if the model closely approximates the phenomenon under study (Coffman \& MacCallum, 2005). Thus, we followed Bollen (1989) in implementing a procedure for path analysis where a latent variable can be specified with only one indicator, via a reliability correction for measurement error.

We estimated the hypothesized model in Stata13, using structural equation modeling (SEM) with maximum likelihood estimation and the delta method procedure (i.e., the Sobel test). We computed not only normal-based but also robust standard errors, in an attempt to mitigate potential heteroskedasticity concerns (Hayes \& Cai, 2007). A number of authors suggest that the SEM approach to mediation analysis is enhanced when alternative models are compared to the hypothesized model (e.g., James, Mulaik, \& Brett, 2006; Mathieu \& Taylor, 2006). Consequently, we estimated several alternative models against the hypothesized model to be sure that the results are derived from the best-fitting model. We also paid special attention to concerns 


\section{LEARNING GOAL ORIENTATION AND LEADERSHIP RECOGNITION}

about causal claims and endogeneity, which may cast serious threat on the validity of mediation analyses (Antonakis et al., 2010; MacKinnon, Fairchild, \& Fritz, 2007).

\section{Results}

Summary statistics and correlations are presented in Table 1. Generally, the pattern of correlations follows the expected direction. First, in order to ensure that the estimated effect sizes are derived from the best-fitting mediation model (e.g., Mathieu \& Taylor, 2006), we estimated a set of alternative models against the hypothesized model. The fit statistics for these models are presented in Table 2. When all key variables were allowed to connect to each other, the model was saturated and so fit statistics are unavailable (Model 0). The hypothesized model (Model 1) exhibited very good fit with the data $\left(\chi^{2}(d f=1 n=268)=1.66\right.$, n.s.; RMSEA $=.05 ;$ CFI $=1.00$; SRMR $=.001)$. We compared the hypothesized model with a model in which the direct effect of LGO on leadership recognition was constrained to zero (Model 2 in Table 2). The results show that this model is marginally inferior to the hypothesized model $\left(\Delta \chi^{2}(d f=1 n=268)=3.15, p\right.$ $<.10)$. Further, we compared the hypothesized model with an alternative model in which the nonsignificant relationship between LGO and contextual role behavior was constrained to zero (Model 3). Result shows that dropping this direct effects did not reduce the fit of the model $\left(\Delta \chi^{2}(d f=1 n=268)=0.55, n\right.$.s. $)$. Finally, Model 4 shows the fit statistics for a model that constrains the effects of LGO on both contextual role behavior and leadership recognition to zero; this model is not inferior to the hypothesized $\left(\Delta \chi^{2}(d f=2 n=268)=3.96\right.$, n.s. $)$. These findings lend preliminary support for a two-stage mediation mechanism indirectly linking LGO and leadership recognition.

Insert Tables $1 \& 2$ about here 
In an attempt to account for potential endogeneity, we compared Model 1 to models in which the disturbances of the endogenous variables were allowed to correlate. The models where we allowed the error terms of contextual role behavior and leadership recognition to correlate were not different from Model $1\left(\Delta \chi^{2}(d f=1 n=268)=1.66, n . s.\right)$. We also attempted this with felt safety and contextual role behavior, but the model did not converge, so we implemented the same procedure on Model 4. The model where we allowed the error terms of felt safety and contextual role behavior to correlate was not different from Model $4\left(\Delta \chi^{2}(d f=2 n=268)=0.82\right.$, n.s.). These results lead us to infer that there is no clear risk of endogeneity in our study (Antonakis et al., 2010).

The results of the SEM analysis performed to test the hypotheses (Model 1 in Table 2) are presented in Table 3. All the direct relationships in our model are significant except for the link between LGO and contextual role behavior. Hypothesis 1, which predicts that felt safety mediates the relationship between LGO and contextual role behavior, is supported $\left(\beta_{\text {indirect }}=\right.$ $0.10, p<.05)$. Hypothesis 2 states that contextual role behavior mediates the positive effect of LGO on leadership recognition. Unexpectedly, the indirect effect of LGO on leadership recognition via contextual role behavior is not significant $\left(\beta_{\text {indirect }}=0.05\right.$, n.s. $)$, probably due to the non-significant link between LGO and contextual role behavior mentioned above. Thus, hypothesis 2 is not supported. Hypothesis 3 states that LGO has a significant total indirect effect on leadership recognition via both safety and contextual role behavior. We do find that LGO has a significant indirect effect on leadership recognition sequentially through felt safety and contextual role behavior $\left(\beta_{\text {indirect }}=0.07, p<.05\right)$. Furthermore, the total indirect effect of LGO on leadership recognition is positive and significant ( $\beta_{\text {indirect }}=0.12, p<.05$ ), supporting 


\section{LEARNING GOAL ORIENTATION AND LEADERSHIP RECOGNITION}

Hypothesis 3. Finally, it is interesting to note the significant total (direct + indirect) effect of LGO on leadership recognition, reported in Table $3\left(\beta_{\text {total }}=0.30, p<0.01\right)$.

As a last step, in order to ensure the validity this mediation process results, we conducted supplementary analyses combining the product of coefficients approach with bootstrapping (MacKinnon, Lockwood, Hoffman, West, \& Sheets, 2002). When standard errors were calculated with 1,000 bootstrap replications, the indirect effect and the total (indirect + direct) effect of LGO on leadership recognition were both significant at the .10 and .05 level, respectively (indirect: $90 \% \mathrm{CI}_{\text {bootstrap }}=[0.00,0.25]$ and total: $\left.95 \% \mathrm{CI}_{\text {bootstrap }}=[0.06,0.53]\right) . \mathrm{In}$ sum, we find support for Hypothesis 1 and 3, but not for Hypothesis 2.

Insert Table 3 about here

\section{Discussion}

The objective of this paper was to examine whether and how LGO influences leadership recognition in self-managed teams. Adopting a social exchange perspective, we investigated two intermediate factors that are relevant to social interaction in this context: felt safety and contextual role behavior. We have argued that whereas LGO-enabled contextual role behavior serves as a resource for teams that is reciprocated with leadership recognition in the social interaction (Hypothesis 2), felt safety plays a critical role in enabling and sustaining this behavior in the first place (Hypothesis 1). Furthermore, felt safety and contextual role behavior jointly mediate the effect of LGO on leadership recognition (Hypothesis 3). Whereas Hypotheses 1 and 3 are supported, to our surprise, Hypothesis 2 is not. We found that felt safety mediates the effect of LGO on contextual role behavior but that, contextual role behavioral alone does not mediate 


\section{LEARNING GOAL ORIENTATION AND LEADERSHIP RECOGNITION}

the effect of LGO on leadership recognition. The indirect effect of LGO on leadership recognition was channeled through both felt safety and contextual role behavior. There is also a robust total effect of LGO on leadership recognition, when both direct and indirect effects are taken into account. Our results can be explained in light of — and shed light to — theory, as we discuss further down.

\section{Theoretical Implications}

We believe that our study contributes to research in several ways. First, scholars have emphasized the need to expand LGO research beyond knowledge or skill acquisition and task performance (Cellar et al., 2011; Payne et al., 2007). We answer these calls by examining the effect of LGO in social domains such as informal leadership. Consistent with prior findings (e.g., Hendricks \& Payne, 2007; Sosik et al., 2004), our results provide converging evidence for the relationship between LGO and leadership, but shed novel light on leadership recognition, that is, social perceptions of others in self-managed teams. Adopting the lens of social exchange theory, we advance research by showing that LGO fosters positive social exchange in self-managed teams, such that focal individuals feel safer and more comfortable to engage in generalized social exchange with contextual role behavior, which makes them more likely to be recognized as leaders in return.

Second and more importantly, by identifying specific processes through which LGO affects leadership recognition, our study also develops knowledge of more proximal, mediating processes that may arise from goal orientation. We found that felt safety and contextual role behavior are both necessary to channel the effect of LGO on leadership recognition. The presence of multiple mediators sequentially linking LGO to social outcomes is suggested by some previous work proposing a relatively long causal chain between trait-like LGO and various 
proximal and distal outcomes (e.g., Payne et al., 2007). As a stable trait, LGO may influence individual behavior first through more proximal psychological states, such as felt safety (George, 1992). This reasoning may help explain the indirect trait-behavior link we found in our study (i.e., indirect relationship between LGO and contextual role behavior). The relationship of LGO with a functional behavioral response (i.e., contextual role behavior) exists, but is mainly mediated by an individual psychological state (i.e., felt safety). In fact, the positive affective states associated with LGO are particularly critical to maintaining self-regulation over time, thus channeling the effect of LGO on behaviors (Diefendorff \& Lord, 2008). Only when a psychological state (e.g., felt safety) and concrete behaviors (e.g., contextual role behavior) are both included in the mediating process, can we capture the fuller picture of the effect of LGO on leadership recognition.

From the perspective of social exchange, these results indicate the importance of more profound understanding of the intermediate processes in social exchange. Specifically, felt safety is necessary to sustain social exchange relationships triggered by LGO, consistent with the claim about the association between emotions and social exchange (Lawler \& Thye, 1999). This finding equally offers insight on further integrating trait and behavioral theories of leadership: whereas specific traits (e.g., LGO) may play a significant role in leadership recognition, their effects need to be channeled by affective states (e.g., felt safety) to observable and enacted behaviors (e.g., contextual role behavior) in specific situations (e.g., self-managed teams; see George, 1992).

In addition, the mediation pattern linking LGO and leadership recognition through the simultaneous presence of both felt safety and contextual role behavior prompts us to explore the multifaceted mechanisms underlying leadership attribution. Is simply engaging in context role 


\section{LEARNING GOAL ORIENTATION AND LEADERSHIP RECOGNITION}

behavior sufficient to deserve the leadership recognition of peers in self-managed teams?

Probably not. In fact, individuals may engage in contextual role behavior for different reasons. For example, a performance goal orientation (PGO), characterized by the drive to demonstrate competence, may also relate positively to contextual role behavior (Chiaburu et al., 2007; Porath \& Bateman, 2006). Without formally hypothesizing the effect of PGO in the present study, we did include it as a control, and found that it was positively linked to contextual role behavior. Specifically, our results show a negative direct effect $\left(\beta_{\text {direct }}=-.22, p<.05\right)$ and a positive indirect effect ( $\beta_{\text {indirect }}=.17, p<.05$; through contextual role behavior) of PGO on leadership recognition. Interestingly, these effects canceled each other in the end, rendering the total effect of PGO insignificant $\left(\beta_{\text {total }}=-.06\right.$, n.s.). Seemingly, to be recognized as a leader, what matters is not only engaging in certain behaviors, but also the driver of these behaviors. When individuals enact certain behaviors driven by the desire to appear competent, others may not necessarily recognize these focal individuals as leaders because they may detect the underlying intention and discount the value of the behavior (see also Dasborough \& Ashkanasy, 2002). It appears that leadership recognition stems not just from behaviors but also from the emotional status and authenticity of the person engaging in these behaviors (Gardner, Cogliser, Davis, \& Dickens, 2011) ${ }^{1}$

In sum, we contribute to LGO theory by showing LGO's relevance not only for intrapersonal processes such as individuals' learning and development, but also for interpersonal processes and outcomes implicated in social exchange. Simultaneously, we contribute to social exchange theory by showing the relevance of intrapersonal traits and states, such as LGO and felt safety, for social exchange (Emerson, 1976; Shore et al., 2009). Going beyond leader-member

\footnotetext{
${ }^{1}$ We thank an anonymous reviewer for drawing our attention to this interesting point.
} 


\section{LEARNING GOAL ORIENTATION AND LEADERSHIP RECOGNITION}

exchange (LMX) research, which has been conducted almost entirely on formal leader-follower (manager-subordinate) dyads (Dulebohn, Bommer, Liden, Brouer, \& Ferris, 2012; Graen, \& Uhl-Bien, 1995), we elucidate the generalized (rather than dyadic) exchange process that produces informal leadership in teams absent of formal leadership structures.

\section{Practical Implications}

Practically speaking, our findings suggest that to be recognized as a leader in selfmanaged teams, individuals need not only to engage in contextual role behavior, but also to maintain a learning orientation, so that others' leadership attributions are sustained. LGO can serve as an important criterion for selecting members of self-managed teams: fostering felt safety and contextual role behavior, LGO makes team members more leader-like in the eyes of their peers. Our model also offers insight on developing leadership for the self-managed team contexts. Although LGO tends to be a stable trait, it may be possible to change and develop (Dweck, 2006; VandeWalle, 2001). Organizations can help employees cultivate a more learningoriented mindset by implementing seminars and training tools designed to show that skills can be learned, and that mistakes are a natural step in the learning process. Training interventions (Kozlowski \& Bell, 2006) as well as authority and reward structures (Ames, 1992) have been shown to help foster a learning orientation.

Organizational programs can also emphasize specific attitudinal and behavioral tactics by coaching people how to feel safer and voluntarily engage in contextual role behavior, so that the regulatory outcomes of LGO can be directly transmitted toward more effective leadership. While we theorize and certainly find individual differences in safety in our sample (see also Nembhard \& Edmondson, 2006), many authors have considered psychological safety to be a group-level state that can be shaped with practice, coaching, and organizational support (Edmondson, 1999). 


\section{LEARNING GOAL ORIENTATION AND LEADERSHIP RECOGNITION}

Therefore, safety in teams could also be boosted in order to facilitate engagement in contextual role behavior, which is beneficial to team functioning.

\section{Limitations and Future Research}

Our study needs to be viewed in light of certain limitations. In order to test a process model, we collected data at two different time points and, at Time 2, from two different sources. Additionally, we attempted to control for endogeneity in our statistical analyses. Nevertheless, nonexperimental designs cannot assure that the causality links are fully established. Strictly speaking, only the link between LGO and felt safety meets the temporal condition of causality (Kenny, 1979). Because the trait-like LGO is quite stable (Button et al., 1996) and can be considered an exogenous variable (Gong \& Fan, 2006), we believe that the causal claims between LGO and subsequent variables remain sound in the present study (Antonakis et al., 2010). For future research, we encourage longitudinal designs with multiple time points so as to fully comprehend the processes through which causal relationships between LGO and leadership recognition arise.

Another potential limitation is that we specified and operationalized our model at the individual level, while our data were nested within teams. This was warranted since our theoretical focus was at the individual level, and not necessarily at the collective influences on this process. Of course, we have controlled for potential collective influences by introducing team-level fixed effects in our model (Antonakis et al., 2010; Cameron \& Trivedi, 2005). Despite controlling for upper-level influences, we might not have captured the full complexity of teamlevel effects on relationships between individual-level variables. In order to obtain more refined understanding of such compound processes, interested researchers may consider adopting multilevel models that fit the specifications of levels of theory, and incorporate team-level 


\section{LEARNING GOAL ORIENTATION AND LEADERSHIP RECOGNITION}

factors (Klein \& Kozlowski, 2000). Finally, we collected data from MBA teams, which may lead one to question the generalizability of our findings. Because our sample consisted of individuals with multiple years of work experience engaged in real-life teamwork and professional collaboration, we are confident of the generalizability of our results to other knowledge-based work settings. However, we invite future research to replicate our study.

\section{Conclusion}

By answering the questions whether and how LGO links to leadership recognition in selfmanaged teams, this study has contributed with a deeper understanding of goal orientation's social outcomes. Adopting and contributing to the social exchange perspective, we have shown that LGO is related to leadership recognition via the mediation of felt safety and contextual role behavior, and only when both mechanisms are at work. Making a case for the importance of intrapersonal regulation in channeling the effect of LGO on interpersonal processes such as leadership recognition, we hope this study lays the groundwork for future research on goal orientation and leadership. 


\section{LEARNING GOAL ORIENTATION AND LEADERSHIP RECOGNITION}

\section{References}

Ames, C. (1992). Classrooms: Goals, structures, and student motivation. Journal of Educational Psychology, 84, 261-271.

Antonakis J., Bendahan S., Jacquart P., \& Lalive R. (2010). On making causal claims: A review and recommendations. The Leadership Quarterly, 21, 1086-1120.

Ashford, S. J., Blatt, R., \& VandeWalle, D. (2003). Reflections on the looking glass: A review of research on feedback-seeking behavior in organizations. Journal of Management, 29, 773 799. Batson, C. D., \& Powell, A. A. (2003). Altruism and prosocial behavior. In T. Millon \& M. Lerner (Eds). Handbook of Psychology. Vol. 5. pp. 463-484. John Wiley \& Son.

Bass, B.M. (1990). The Bass \& Stogdill's handbook of leadership: Theory, research, and managerial applications. New York: Free Press.

Bollen, K. A. (1989). Structural equations with latent variables. New York: Wiley

Borman, W. C., \& Motowidlo, S. J. (1993). Expanding the criterion domain to include elements of contextual performance. In N. Schmitt, W. C. Borman, and associates (Eds.), Personnel selection in organizations, 71-98. San Francisco: Jossey-Bass.

Brett, J. F., \& Vandewalle, D. (1999). Goal orientation and goal content as predictors of performance in a training program. Journal of Applied Psychology, 84, 863-873.

Brown, D. J. (2012). In the minds of followers: Follower-centric approaches to leadership. In D. V. Day \& J. Antonakis (Eds.), The nature of leadership, 331-362, Thousand Oaks, CA: Sage

Bunderson, J. S., \& Boumgarden, P. (2010). Structure and learning in self-managed teams: Why "bureaucratic" teams can be better learners. Organization Science, 21(3), 609-624.

Burns, T. (1973). A structural theory of social exchange. Acta Sociologica, 16(3), 188-208. 


\section{LEARNING GOAL ORIENTATION AND LEADERSHIP RECOGNITION}

Button, S. B., Mathieu, J. E., \& Zajac. D. M. (1996). Goal orientation in organizational research: A conceptual and empirical foundation. Organizational Behavior and Human Decision Processes, 67, 26-48.

Cameron, A. C., \& Trivedi, P. K. (2005). Microeconometrics: Methods and applications. New York: Cambridge University Press.

Carmeli, A., \& Gittel, J. H. (2009). High-quality relationships, psychological safety, and learning from failures in work organizations. Journal of Organizational Behavior, 30, 709-729.

Cellar, D. F., Stuhlmacher, A. F., Young, S. K., Fisher, D. M., Adair, C. K., Haynes, S., Twichell, E., Arnold, K. A., Royer, K., Denning, B. L., \& Riester, D. (2011). Trait goal orientation, self-regulation, and performance: A meta-analysis. Journal of Business and Psychology, 26, 467-483.

Chan, D. (1998). Functional relations among constructs in the same content domain at different levels of analysis: A typology of composition models. Journal of Applied Psychology, 83, 234-246.

Chen, G., Gully, S. M., Whiteman, J. A., \& Kilcullen, R. N. (2000). Examination of relationships among trait-like individual differences, state-like individual differences, and learning performance. Journal of Applied Psychology, 85, 835-847.

Chiaburu, D. S., Marinova, S. V., Lim, A. S. (2007). Helping and proactive extra-role behaviors: The influence of motives, goal orientation, and social context. Personality and Individual Differences, 43, 2282-2293.

Coad, A. F. \& Berry, A. J. (1998). Transformational leadership and learning orientation. Leadership \& Organization Development Journal, 19, 164-172. 


\section{LEARNING GOAL ORIENTATION AND LEADERSHIP RECOGNITION}

Coffman, D. L., \& MacCallum, R. C. (2005). Using parcels to convert path analysis models into latent variable models. Multivariate Behavioral Statistics, 40, 235-259.

Crant, J. M. (2000). Proactive behavior in organizations. Journal of Management, 26, 435-462.

Cronshaw, S. E., \& Lord, R. G. (1987). Effects of categorization, attribution, and encoding processes on leadership perceptions. Journal of Applied Psychology, 72, 97-106.

Cropanzano, R., \& Mitchell, M. S. (2005). Social exchange theory: An interdisciplinary review. Journal of Management, 31(6), 874-900.

Daily, C. M., Certo, S. T., \& Dalton, D. R. (2000). International experience in the executive suite: the path to prosperity? Strategic Management Journal, 21(4), 515-523.

Dasborough, M. T., \& Ashkanasy, N. M. (2002). Emotion and attribution of intentionality in leader-member relationships. The Leadership Quarterly, 13, 615-634.

DeRue, D. S., \& Ashford, S. J. (2010). Who will lead and who will follow? A social process of leadership identity construction in organizations. Academy of Management Review, 35, 627647.

DeRue, D. S., \& Morgeson, F. P. (2007). Stability and change in person-team and person-role fit over time: The effects of growth satisfaction, performance, and general self-efficacy. Journal of Applied Psychology, 92, 1242-1253.

DeRue, D. S. \& Wellman, N. (2009). Developing leaders via experience: The role of developmental challenge, learning orientation, and feedback. Journal of Applied Psychology, $94,859-875$.

Diefendorff, J. M., \& Lord, R. G. (2008). Goal-striving and self- regulation processes. In R. Kanfer, G. Chen, \& R. D. Pritchard (Eds.), Work motivation: Past, present, and future (pp. 151-196). New York: Routledge. 


\section{LEARNING GOAL ORIENTATION AND LEADERSHIP RECOGNITION}

Dragoni, L., Tesluk, P.E., Russell, J.E.A., \& Oh, I. (2009). Understanding managerial development: Integrating developmental assignments, learning orientation, and access to developmental opportunities in predicting managerial competencies. Academy of Management Journal, 52, 731-743.

Dulebohn, J. H., Bommer, W. H., Liden, R. C., Brouer, R. L., \& Ferris, G. R. (2012). A metaanalysis of antecedents and consequences of leader-member exchange integrating the past with an eye toward the future. Journal of Management, 38(6), 1715-1759.

Dweck, C. S. (1986). Motivational processes affecting learning. American Psychologist, 41, 1040-1048.

Dweck, C. S. (2006). Mindset: The new psychology of success. New York: Random House.

Dweck, C. S., \& Leggett, E. L. (1988). A social-cognitive approach to motivation and personality. Psychological Review, 95, 256-273.

Dykman, B. M. (1998). Integrating cognitive and motivational factors in depression: Initial tests of a goal-orientation approach. Journal of Personality and Social Psychology, 74, 139-158.

Edmondson, A. (1999). Psychological safety and learning behavior in work teams.

Administrative Science Quarterly, 44, 350-383.

Edmondson, A. C., \& Lei, Z. (2014). Psychological safety: The history, renaissance, and future of an interpersonal construct. Annual Review of Organizational Psychology and Organizational Behavior, 1(1), 23-43.

Edmondson, A., \& Roloff, K. (2008). Overcoming barriers to collaboration: Psychological safety and learning in diverse teams. In E. Sales, G. G. Goodwin \& C. S. Burke. (Eds.), Team effectiveness in complex organizations: Cross-disciplinary perspectives and approaches (pp. 183-208). Mahwah, N.J.: Lawrence Erlbaum Associates. 


\section{LEARNING GOAL ORIENTATION AND LEADERSHIP RECOGNITION}

Emerson, R. M. (1976). Social exchange theory. Annual Review of Sociology, 335-362.

Erez, A., Lepine, J. A., \& Elms, H. (2002). Effects of rotated leadership and peer evaluation on the functioning and effectiveness of self-managed teams: a quasi-experiment. Personnel Psychology, 55(4), 929-948

Fleishman, E. A., Mumford, M. D., Zaccaro, S. J., Levin, K. Y., Korotkin, A. L., \& Hein, M. B. (1991). Taxonomic efforts in the description of leader behavior: a synthesis and functional interpretation. The Leadership Quarterly, 2, 245-287.

Foti, R. J., \& Hauenstein, N. M. A. (2007). Pattern and variable approaches in leadership emergence and effectiveness. Journal of Applied Psychology, 92, 347-355.

Gardner, W. L., Cogliser, C. C., Davis, K. M., \& Dickens, M. P. (2011). Authentic leadership: A review of the literature and research agenda. The Leadership Quarterly, 22(6), 1120-1145.

George, J. M. (1992). The role of personality in organizational life: Issues and evidence. Journal of Management, 18, 185-213.

Gong, Y. \& Fan, J. (2006). Longitudinal examination of the role of goal orientation in crosscultural adjustment. Journal of Applied Psychology, 91, 176-184.

Graen, G. B., \& Uhl-Bien, M. (1995). Relationship-based approach to leadership: Development of leader-member exchange (LMX) theory of leadership over 25 years: Applying a multilevel multi-domain perspective. The Leadership Quarterly, 6(2), 219-247.

Hayes, A. F., \& Cai, L. (2007). Using heteroscedasticity-consistent standard error estimators in OLS regression: An introduction and software implementation. Behavior Research Methods, $39,709-722$.

Hendricks, J. W., \& Payne, S. C. (2007). Beyond the Big Five: Leader goal orientation as a predictor of leadership effectiveness. Human Performance, 20, 317-344. 


\section{LEARNING GOAL ORIENTATION AND LEADERSHIP RECOGNITION}

James, L. R., Demaree, R. G., \& Wolf, G. (1984). Estimating within-group interrater reliability with and without response bias. Journal of Applied Psychology, 69, 85-98.

James, L. R., Mulaik, S. A., \& Brett, J. M. (2006). A tale of two methods. Organizational Research Methods, 9, 233-244.

Janssen, O., \& Prins, J. (2007). Goal orientations and the seeking of different types of feedback information. Journal of Occupational and Organizational Psychology, 80, 235-249.

Janssen, O., \& Van Yperen, N. W. (2004). Employees' goal orientations, the quality of leadermember exchange, and the outcomes of job performance and job satisfaction. Academy of Management Journal, 47, 368-384.

Kahn, W. A. (1990). Psychological conditions of personal engagement and disengagement at work. Academy of Management Journal, 33, 692-724.

Kenny, D. A. (1979). Correlation and causality. New York: Wiley-Interscience.

Klein, K. J., \& Kozlowski, S. W. J. (2000). From micro to meso: Critical steps in conceptualizing and conducting multilevel research. Organizational Research Methods, 3, 211-236.

Kozlowski, S. W. J., \& Bell, B. S. (2006). Disentangling achievement orientation and goal setting: Effects on self-regulatory processes. Journal of Applied Psychology, 91, 900-916.

Lawler, E. J., \& Thye, S. R. (1999). Bringing emotions into social exchange theory. Annual Review of Sociology, 217-244.

LePine, J. A., Hanson, M. A., Borman, W. C., \& Motowidlo, S. J. (2000). Contextual performance and teamwork: Implications for staffing. Research in Personnel and Human Resources Management, 19, 53-90.

Lord, R. G. (1977). Functional leadership behavior: Measurement and relation to social power 


\section{LEARNING GOAL ORIENTATION AND LEADERSHIP RECOGNITION}

and leadership perceptions. Administrative Science Quarterly, 22, 114-133.

MacKinnon, D. P., Fairchild, A. J., \& Fritz, M. S. (2007). Mediation analysis. Annual Review of Psychology, 58, $593-614$.

MacKinnon, D.P., Lockwood, C.M., Hoffman, J.M., West, S.G., \& Sheets, V. (2002). A comparison of methods to test mediation and other intervening variable effects. Psychological Methods, 7, 83-104.

Mann, R. D. (1959). A review of the relationships between personality and performance in small groups. Psychological Bulletin, 56, 241-270.

Mathieu, J. E. \& Taylor, S. R. (2006). Clarifying conditions and decision points for meditational type inferences in organizational behavior. Journal of Organizational Behavior, 27, 10311056.

Meindl, J. R. (1995). The romance of leadership as a follower-centric theory: A social constructionist approach. The Leadership Quarterly, 6, 329-341.

Morgeson, F. P., DeRue, D. S. \& Karam, E. P. (2010). Leadership in teams: A functional approach to understanding leadership structures and processes. Journal of Management, 36, 5-39.

Nembhard, I. M., \& Edmondson, A. C. (2010). Psychological safety: A foundation for speaking up, collaboration, and experimentation in organizations. In K.S. Cameron \& G.M. Spreitzer (Eds.), The Oxford Handbook of Positive Organizational Scholarship (pp. 490-503). New York: Oxford University Press.

Parsons, T. 1951, The Social System. Glencoe, Illinois: The Free Press.

Payne, S., Youngcourt, S. S., \& Beaubien, J. M. (2007). A meta-analytic examination of the goal orientation nomological net. Journal of Applied Psychology, 92, 128-150. 


\section{LEARNING GOAL ORIENTATION AND LEADERSHIP RECOGNITION}

Podsakoff, P. M., MacKenzie, S. B., \& Podsakoff, N. P. (2012). Sources of method bias in social science research and recommendations on how to control it. Annual Review of Psychology, 63, 539-569.

Poortvliet, P. M., \& Darnon, C. (2010). Toward a more social understanding of achievement goals: The interpersonal effects of mastery and performance goals. Current Directions in Psychological Science, 19, 324-328.

Poortvliet, P. M., Janssen, O., Van Yperen, N. W., \& Van de Vliert, E. (2007). Achievement goals and interpersonal behavior: How mastery and performance goals shape information exchange. Personality and Social Psychology Bulletin, 33, 1435-1447.

Poortvliet, P. M., Anseel, F., Janssen, O., Van Yperen, N. W., \& Van de Vliert, E. (2012). Perverse effects of other-referenced performance goals in an information exchange context. Journal of Business Ethics, 106(4), 401-414.

Porath, C. L., \& Bateman, T. S. (2006). Self-regulation: From goal orientation to job performance. Journal of Applied Psychology, 91, 185-192.

Porter, C. O. (2005). Goal orientation: Effects on backing up behavior, performance, efficacy, and commitment in teams. Journal of Applied Psychology, 90, 811-818.

Preacher, K. J., Zyphur, M. J., \& Zhang, Z. (2010). A general multilevel SEM framework for assessing multilevel mediation. Psychological methods, 15(3), 209-233.

Shore, L. M., Coyle-Shapiro, J. A. M., Chen, X. P., \& Tetrick, L. E. (2009). Social exchange in work settings: Content, process, and mixed models. Management and Organization Review, 5(3), 289-302.

Sosik, J. J., Godshalk, V. M., \& Yammarino, F. J. (2004). Transformational leadership, learning goal orientation, and expectations for career success in mentor-protégé relationships: A 


\section{LEARNING GOAL ORIENTATION AND LEADERSHIP RECOGNITION}

multiple levels of analysis perspective. The Leadership Quarterly, 15, 241-261.

Taggar, S., Hackett, R. \& Saha, S. (1999). Leadership emergence in autonomous work teams: Antecedents and outcomes. Personnel Psychology, 52, 899-926.

VandeWalle, D. (2001). Goal orientation: Why wanting to look successful doesn't always lead to success. Organizational Dynamics, 30, 162-171

VandeWalle, D, Brown S. P., Cron, W. L., \& Slocum, J. W. (1999). The influence of goal orientation and self-regulation tactics on sales performance: A longitudinal field test. Journal of Applied Psychology, 84, 249-259.

VandeWalle, D., \& Cummings, L. L. (1997). A test of the influence of goal orientation on the feedback-seeking process. Journal of Applied Psychology, 82, 390-400.

Willer, R., Flynn, F. J., \& Zak, S. (2012). Structure, identity, and solidarity a comparative field study of generalized and direct exchange. Administrative Science Quarterly, 57(1), 119-155.

Yamagishi, T., \& Cook, K. S. (1993). Generalized exchange and social dilemmas. Social Psychology Quarterly, 235-248. 
LEARNING GOAL ORIENTATION AND LEADERSHIP RECOGNITION

Table 1

Summary Statistics and Correlations ${ }^{a}$

\begin{tabular}{|c|c|c|c|c|c|c|c|c|c|}
\hline Variable & $\bar{M}$ & $S D$ & 1 & 2 & 3 & 4 & 5 & 6 & 7 \\
\hline 1. Age & 27.79 & 2.01 & & & & & & & \\
\hline 2. Sex $(0=$ Male; $1=$ Female $)$ & .28 & .45 & $-.18^{* *}$ & & & & & & \\
\hline 3. Number of countries lived & 2.19 & 1.24 & .03 & .03 & & & & & \\
\hline 4. Performance goal orientation & 5.12 & .83 & -.01 & -.01 & -.02 & & & & \\
\hline 5. Learning goal orientation (LGO) & 6.05 & .69 & .00 & -.07 & .07 & $.21^{* *}$ & & & \\
\hline 6. Felt safety & 5.46 & .83 & $-.14^{*}$ & -.11 & -.03 & .03 & $.16^{* *}$ & & \\
\hline 7. Contextual role behavior & 5.10 & .84 & -.01 & -.06 & .03 & $.13^{*}$ & .10 & $.34^{* *}$ & \\
\hline 8. Leadership perception & 4.42 & .98 & .04 & $-.18^{* *}$ & $.17^{* *}$ & -.01 & .11 & $.26^{* *}$ & $.51^{* *}$ \\
\hline
\end{tabular}

${ }^{*} p<.05,{ }^{* *} p<.01$

${ }^{a} . n=287$ 
LEARNING GOAL ORIENTATION AND LEADERSHIP RECOGNITION

Table 2

Fit Statistics for Hypothesized and Alternative Models ${ }^{b}$

\begin{tabular}{|c|c|c|c|c|c|c|c|}
\hline Model & $\chi^{2}$ & $d f$ & $p>\chi^{2}$ & $\Delta \chi^{2}$ & RMSEA & CFI & SRMR \\
\hline 0. $\quad$ Fully saturated (all model variables are linked) & - & 0 & - & - & - & - & - \\
\hline 1. Hypothesized model (remove FS $\rightarrow$ LR from Model 0) & 1.662 & 1 & 0.197 & & 0.050 & 0.998 & 0.001 \\
\hline 2. Remove LGO $\rightarrow$ LR from Model 1 & 4.807 & 2 & 0.090 & $3.15^{\dagger}$ & 0.072 & 0.989 & 0.003 \\
\hline 3. Remove LGO $\rightarrow$ CRB from Model 1 & 2.210 & 2 & 0.331 & 0.55 & 0.020 & 0.999 & 0.002 \\
\hline 4. Remove LGO $\rightarrow$ LR and LGO $\rightarrow$ CRB from Model 1 & 5.626 & 3 & 0.131 & 3.96 & 0.057 & 0.990 & 0.003 \\
\hline
\end{tabular}

${ }^{*} p<.05,{ }^{* *} p<.01$

$b . \mathrm{LGO}=$ Learning goal orientation; $\mathrm{FS}=$ Felt safety; $\mathrm{CRB}=$ Contextual role behavior; $\mathrm{LR}=$ Leadership recognition; $\chi^{2}=\mathrm{Chi}$-square; $d f=$ degrees of freedom; $\Delta \chi^{2}=$ change in $\chi^{2}$ over Model 1; RMSEA = root-mean-square error of approximation; CFI = comparative fit index; SRMR = standardized root-mean square residual. 
LEARNING GOAL ORIENTATION AND LEADERSHIP RECOGNITION

Table 3

Results of Path Analysis - Hypothesized Model $^{c}$

\begin{tabular}{lccc}
\hline & Estimate & $\begin{array}{c}\text { Normal-based CI } \\
(95 \%)\end{array}$ & $\begin{array}{c}\text { Robust CI } \\
(95 \%)\end{array}$ \\
\hline Direct Effects & & & \\
$\mathrm{LGO} \rightarrow \mathrm{FS}$ & $0.29(.09)^{* *}$ & $0.11,0.46$ & $0.10,0.47$ \\
$\mathrm{LGO} \rightarrow \mathrm{CRB}$ & $0.07(.09)$ & $-0.11,0.24$ & $-0.11,0.25$ \\
$\mathrm{LGO} \rightarrow \mathrm{LR}$ & $0.17(.10)^{\dagger}$ & $-0.02,0.36$ & $0.01,0.34$ \\
$\mathrm{CRB} \rightarrow \mathrm{LR}$ & $0.75(.08)^{* *}$ & $0.59,0.91$ & $0.59,0.92$ \\
$\mathrm{FS} \rightarrow \mathrm{CRB}$ & $0.35(.10)^{* *}$ & $0.15,0.55$ & $0.06,0.63$ \\
& & & \\
Indirect Effects & & & $-0.01,0.21$ \\
$\mathrm{LGO} \rightarrow \mathrm{FS} \rightarrow \mathrm{CRB}$ & $0.10(.04)^{*}$ & $0.01,0.18$ & $-0.09,0.18$ \\
LGO $\rightarrow$ CRB $\rightarrow$ LR & $0.05(.07)$ & $-0.08,0.18$ & $-0.01,0.16$ \\
LGO $\rightarrow$ FS $\rightarrow$ CRB $\rightarrow$ LR & $0.07(.03)^{*}$ & $0.01,0.14$ & $0.02,0.23$ \\
Total Indirect Effect LGO $\rightarrow$ LR & $0.12(.05)^{*}$ & $0.00,0.25$ & \\
& & & $0.11,0.49$ \\
Total Effects & & & \\
Total (Direct + Indirect) Effect LGO $\rightarrow$ LR & $0.30(.11)^{* *}$ & $0.08,0.51$ & \\
& & & \\
\hline
\end{tabular}

${ }^{*} p<.05,{ }^{* *} p<.01$

$c$. Reliability estimates were used to correct for measurement error (Bollen, 1989). CI = confidence intervals; LGO = Learning goal orientation; FS = Felt safety; $\mathrm{CRB}=$ Contextual role behavior; $\mathrm{LR}=$ Leadership recognition. Team dummies (team $n=36$ ), as well as individual-level control variables (age, sex, number of countries lived, performance goal orientation) included but not shown for ease of presentation. All endogenous variables were regressed on all control variables, 
Figure 1

\section{Hypothesized Model, Measures, and Results ${ }^{d}$}

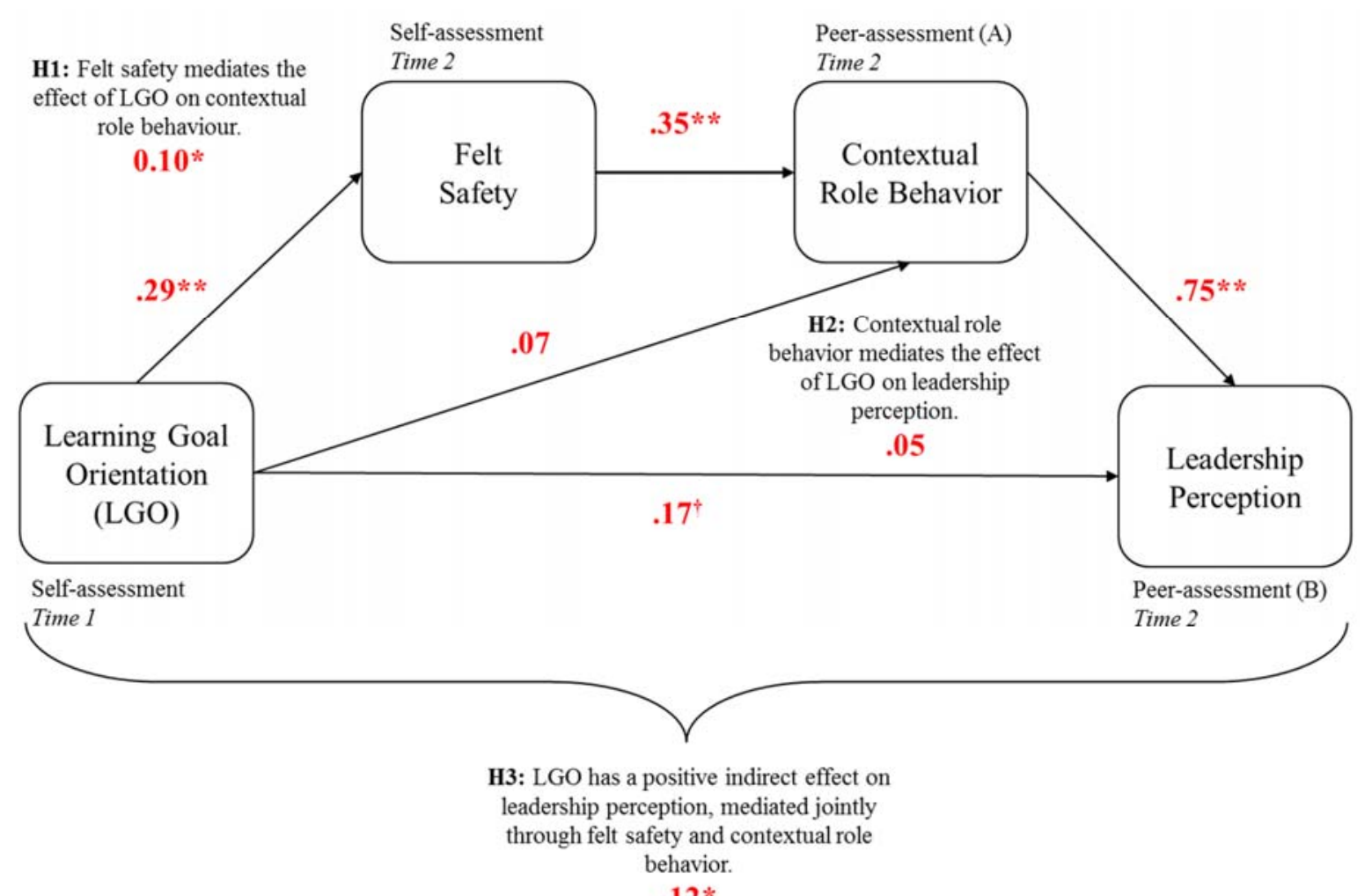

${ }^{*} p<.05,{ }^{* *} p<.01$

${ }^{d}$. $\mathrm{H}$ refers to Hypothesis (e.g., $\mathrm{H} 2=$ Hypothesis 2 ). Peer-assessment measures were randomly partitioned so that scores on contextual role behavior were provided by one-half of the team members (A), and scores on leadership recognition were provided by the other half (B). Learning goal orientation and felt safety are self-reported measures. Data collection at Time 1 precedes data collection at Time 2 by two and a half months. The presented estimates of coefficients refer to Model 1 (hypothesized) in Table 3. The only allowed paths between the presented variables are shown. Team dummies (team $n=36$ ), as well as individuallevel control variables (age, sex, number of countries lived, performance goal orientation) included but not shown for ease of presentation. All endogenous variables were regressed on all control variables, and the exogenous variable LGO was allowed to correlate with all control variables. Individual $n=268$. Significance levels assuming normal-based standard errors. 